\title{
Pteridine modulation of lead inhibition of uroporphyrinogen synthesis in erythroid precursor cells
}

\author{
Warren W. Ku and Walter N. Piper \\ Toxicology Program. Department of Environmental and Industrial Health and Depariment of \\ Pharmacology, Medical School, University of Michigan, Ann Arbor, MI (U.S.A.)
}

(Received 13 June 1989)

(Accepted 29 October 1989)

Key words Lead toxicity; Erythroleukemia cells; Uroporphyrinogen synthesis; Pteroylpolyglutamates

\section{SUMMARY}

The role of nutritional factors on heme synthesis and their influence on the development of anemia in the bone marrow during lead exposure is unclear. Previous reports suggested that pteridines could regulate the formation of uroporphyrinogen, a step midway along the heme synthetic pathway. Studies were undertaken to determine if pteridines could modulate lead inhibition of uroporphyrinogen synthesis in erythroid precursor cells. Pteroylpolyglutamates of various glutamate chain lengths were tested for the ability to protect against lead inhibition of uroporphyrinogen I (URO) synthase prepared from murine erythroleukemia cells (MELC). Pteroylpentaglutamate, the major endogenous polyglutamate form by chain length found to be present in MELC, afforded rapid and specific protection of URO synthase against lead inhibition. MELC are expected to be a useful in vitro model for studying the role of endogenous folates on uroporphyrinogen synthesis and heme formation in erythroid precursor cells following lead exposure.

\section{INTRODUCTION}

The role of various physiological factors that regulate heme synthesis and/or influence the development of anemia in the bone marrow during lead $(\mathrm{Pb})$ exposure has been sparsely investigated. Previous studies in liver demonstrated that oxidized polyglutamate derivatives of folic acid protected against $\mathrm{Pb}$ inhibition of uroporphyrinogen I (URO) synthase (EC 4.3.1.8) [1]. As a result of the rather low levels of URO synthase activity found in liver and other tissues, it is believed that the synthesis of

Address for correspondence: W.N. Piper, Toxicology Program, Department of Environmental and Industrial Health, University of Michigan, Ann Arbor, MI 48109-2029, U.S.A. 
uroporphyrinogen may be potentially rate-limiting for the biosynthesis of heme. Consequently, the endogenous folate content and regulation of pteroylpolyglutamate synthesis/catabolism are anticipated to be important factors modulating the susceptibility of bone marrow heme synthesis to inhibition by $\mathrm{Pb}[2]$.

Most previous studies concerning the etiology of drug/toxicant-associated anemia and its relationship to the biosynthesis of heme have been conducted with the mature red blood cell, which is not actively engaged in heme synthesis. It is anticipated that more relevant information could be obtained by focusing study on the bone marrow. It is known that premature erythroid precursor cells are highly susceptible to the toxic effects of $\mathrm{Pb}$. As a result of the complex cellular heterogeneity of bone marrow in vivo, controlled study of this cellular target is rather difficult. Murine erythroleukemia cells (MELC) are crythroid precursor cclls which, when cultured in the presence of certain chemicals (e.g. DMSO, hexamethylene-bis(acetamide) [HMBA]) [3,4], undergo changes similar to normal erythrocyte maturation, including the synthesis of heme and hemoglobin [5]. It is anticipated that MELC will be a useful in vitro model to study drug/toxicant interactions during erythropoiesis. In the present study, this in vitro system was evaluated for its potential usefulness as a model to study folate regulation of uroporphyrinogen synthesis and heme formation in bone marrow during $\mathrm{Pb}$ exposure.

\section{MATERIALS AND METHODS}

\section{Cell culture}

The murine erythroleukemia cell line (MELC), clone 745A, was obtained from the Institute for Medical Research, Camden, NJ. Spinner cultures were maintained at $37^{\circ} \mathrm{C}$ in Iscove's minimum essential medium supplemented with $5 \%(\mathrm{v} / \mathrm{v} /)$ defined bovine calf serum (Hyclone Laboratories, Inc., Logan, UT). Induction of differentiation was achicved by addition of a stock solution of hexamethylene-bis(acetamide) (HMBA) (Sigma Chemical Co., St. Louis, MO) to a final medium concentration of $3 \mathrm{mM}$ and maintenance of cultures for 4 days.

\section{Subcellular fractionation}

MELC pellets were lysed in distilled deionized water and homogenized in $50 \mathrm{mM}$ Tris-HCl buffer ( $\mathrm{pH} \mathrm{8.0)}$. After sequential centrifugation, the resulting $100000 \times$ $g$ supernatant (cytosol) served as the enzyme source. MELC cytosol was dialyzed for $24 \mathrm{~h}$ at $4^{\circ} \mathrm{C}$ against $100 \times$ volume of buffer with 4 exchanges. Protein content was determined by the method of Lowry et al. [6].

\section{Uroporphyrinogen I (URO) synthase activity}

Cytosolic URO synthase activity was measured by a modification [7] of the method of Strand et al. [8]. Cytosol was incubated with $100 \mu \mathrm{M}$ porphobilinogen (PBG) (Porphyrin Products, Logan, UT) in $50 \mathrm{mM}$ Tris- $\mathrm{HCl} / 50 \mathrm{mM} \mathrm{KCl}(\mathrm{pH} 7.8)$ at $37^{\circ} \mathrm{C}$ for 
$45 \mathrm{~min}$. Following the addition of ethylacetate/acetic acid (2:1), $1.0 \mathrm{~N} \mathrm{HCl}$ was added and the mixture shaken. After phase separation and standing for $30 \mathrm{~min}$ in room light, porphyrin fluorescence in the lower aqueous phase was determined and compared to a uroporphyrin I standard (Porphyrin Products) using a spectrophotofluorometer.

\section{$\delta$-Aminolevulinic acid dehydratase ( $A L A-D)$ activity}

Cytosolic ALA-D activity was measured by the method of Gibson et al. [9]. The product, porphobilinogen (PBG), was measured spectrophotometrically $(553 \mathrm{~nm}$ ) after reaction with Ehrlich's reagent using a mM extinction coefficient of 61 .

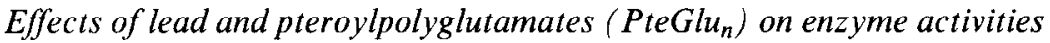

Pteroylpolyglutamates in oxidized form were obtained from Dr. N.G. Nair, University of South Alabama Medical Sciences Foundation, Mobile, AL. Pb as lead acetate and pteroylpolyglutamates as free acids were added to the incubation mixtures as described in the text. Pteroylpolyglutamates exhibited $95 \%$ homogeneity by glutamate chain length as determined hy high-performance liquid chromatography (HPLC) as described by Shane [10].

\section{Pteroylpolyglutamate distribution in MELC}

Endogenous pteroylpolyglutamates in MELC extracts were quantitatively cleaved to $p$-aminobenzoylpolyglutamates and separated according to glutamate chain length by HPLC as described by Shane [10].

\section{Statistics}

Data were analyzed by Student's $t$-test to determine the significance of difference between means.

\section{RESULTS AND DISCUSSION}

The effect of $\mathrm{Pb}$ on uroporphyrinogen synthase was studied in MELC. The results showed that URO synthase activity in untreated cytosol was unaffected by incubation with $50 \mu \mathrm{M} \mathrm{Pb}$ (Table I). Dialysis of cytosol rendered URO synthase activity sensitive to $\mathrm{Pb}$, showing an $80 \%$ decrease in activity in Pb-treated cytosol compared to controls. Thus, MELC cytosol exhibited similarities to hepatic cytosol with respect to the presence of a dialyzable factor conferring protection on URO synthase against inhibition by $\mathrm{Pb}[1]$. The dialyzable factor was postulated to be a derivative of pteroylpolyglutamic acid.

To test this possibility, various pteroylpolyglutamates were tested for the ability to protect URO synthase against inhibition by $\mathrm{Pb}$ in dialyzed cytosol. Although all of the pteroylglutamates tested decreased control URO synthase activity somewhat, only pteroylpentaglutamate $\left(\mathrm{PteGlu}_{5}\right)$ was capable of conferring protection against 
TABLE I

EFFECT OF DIALYSIS AND THE ADDITION OF PTEROYLGLUTAMATES OF VARIABLE CHAIN LENGTHS (PteGlu ${ }_{n}$ ) ON INHIBITION OF UROPORPHYRINOGEN (URO) SYNTHASE BY LEAD

Condition

URO synthase activity

gontrol

(nmol URO/mg protein/45 min)

\begin{tabular}{lccc} 
& Control & $50 \mu \mathrm{M} \mathrm{Pb}$ & \\
\hline No dialysis & $6.70 \pm 0.30$ & $6.88 \pm 0.09$ & 103 \\
Dialysis & $6.65 \pm 0.08$ & $1.53 \pm 0.16$ & 23 \\
Dialysis $^{+}$PteGlu $_{1}{ }^{b}$ & $5.41 \pm 0.23$ & $0.72 \pm 0.17$ & 13 \\
$\quad+$ PteGlu$_{2}$ & $4.35 \pm 0.09$ & $0.75 \pm 0.05$ & 17 \\
$\quad+$ PteGlu $_{4}$ & $4.25 \pm 0.05$ & $0.84 \pm 0.08$ & 20 \\
$\quad$ PteGlu $_{5}$ & $4.25 \pm 0.05$ & $3.42 \pm 0.05 *$ & 80 \\
$\quad+$ PteGlu $_{6}$ & $3.93 \pm 0.05$ & $0.65 \pm 0.05$ & 17 \\
\hline
\end{tabular}

Values are the means \pm SEM for 3 determinations.

hPteroylglutamates were added to dialyzed cytosol at a concentration of $100 \mu \mathrm{M}$.

* Significantly different from dialysis $/ \mathrm{Pb}, P<0.01$.

$\mathrm{Pb}$ inhibition (Table I). A rather high concentration $(100 \mu \mathrm{M})$ of PteGlu f $_{5}$ was required to protect URO synthase from $\mathrm{Pb}$ inhibition. One possible explanation is that the endogenous protective factor is a more potent biological derivative of PteGlus [11]. The results in Figure 1 showed that the protection of URO synthase from Pb inhibition by PteGlu 5 was rapid, with near control levels of uroporphyrinogen formation observed in the first 5 min of incubation. Reduced glutathione (GSH), a dialyzable sulfhydryl compound, was also found to protect against $\mathrm{Pb}$ inhibition of URO synthase but only at millimolar concentrations. This concentration exceeded normal cytosolic GSH levels by at least 100-fold (data not shown).

The specificity of PteGlu $\mathrm{u}_{5}$ for protection of URO synthase against $\mathrm{Pb}$ inhibition was examined by testing the ability of PteGlu $\mathrm{H}_{5}$ to protect another heme biosynthetic enzyme known to be extremely sensitive to $\mathrm{Pb}, \delta$-aminolevulinic acid dehydratase

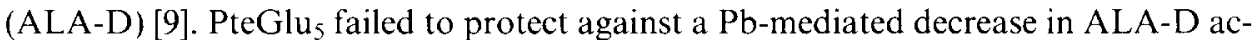
tivity (Table II), suggesting that the protective effect was specific for URO synthase and not merely a $\mathrm{Pb}$-chelating function [1].

Analysis of the distribution of endogenous pteroylglutamates in MELC revealed a mixture of pteroylmono-, tetra-, penta- and hexaglutamate, with pentaglutamate predominating ( $>50 \%$ of total endogenous pteroylglutamate) (Fig. 2). Thus, by glutamate chain length, the pteroylpolyglutamate which protected URO synthase against $\mathrm{Pb}$ inhibition was the predominant endogenous form. Identification of the exact structure of this endogenous pteridine should aid in elucidating the specific mechanism of protection of URO synthase. Such studies are currently in progress. 

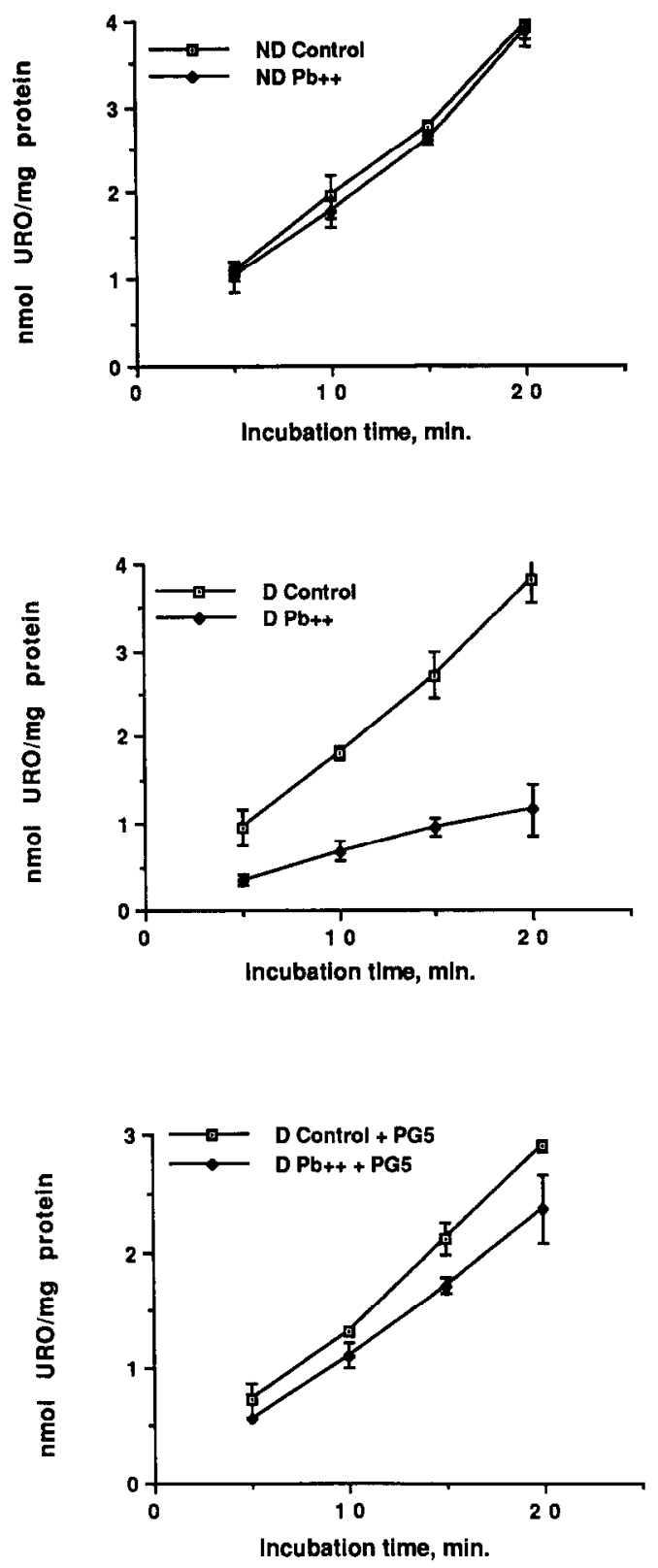

Fig. 1. Effect of dialysis and pteroylpentaglutamate addition on the time-dependent formation of uropor phyrinogen in the presence of $\mathrm{Pb}$. MELC cytosol $(\mathrm{ND}=$ non-dialyzed; $\mathrm{D}=$ dialyzed; $\mathrm{D}+\mathrm{PG} 5=$ dialyzed $+100 \mu \mathrm{M} \mathrm{PteG}\left(\mathrm{u}_{5}\right.$ ) was incubated with porphobilinogen substrate at $37^{\circ} \mathrm{C}$ in the absence or presence of $\mathrm{Pb}$ acetate $(50 \mu \mathrm{M})$ and the reaction terminated at 5.10 .15 and $20 \mathrm{~min}$. Values are the means + SEM for 3 determinations. 


\section{TABLE II}

EFFECT OF THE ADDITION OF PTEROYLPENTAGLUTAMATE (PteGlus) ON INHIBITION OF $\delta$-AMINOLEVULINIC ACID DEHYDRATASE (ALA-D) ACTIVITY BY LEAD

\begin{tabular}{|c|c|c|c|}
\hline \multirow[t]{2}{*}{ Condition } & \multicolumn{2}{|c|}{$\begin{array}{l}\text { ALA-D activity } \\
\text { (nmol } \mathrm{PBC} / \mathrm{mg} \text { protein } / \mathrm{h})\end{array}$} & \multirow[t]{2}{*}{$p_{i}$ Control } \\
\hline & Control & $50 \mu \mathrm{M} \mathrm{Pb}$ & \\
\hline No dialysis & $25.09 \pm 0.35$ & [1. $.89 \pm 0.48$ & 47 \\
\hline Dialysis & $64.00 \pm 0.40$ & $33.75 \pm 0.6 \mathrm{l}$ & 53 \\
\hline Dialysis + PteGlu ${ }_{5}^{\mathrm{b}}$ & $42.67 \pm 1.14$ & $18.36 \pm 1.44$ & 43 \\
\hline
\end{tabular}

"Values are the means \pm SEM for 3 determinations.

hPteroylpentaglutamate was added to dialyzed cytosol at a concentration of $100 \mu \mathrm{M}$.

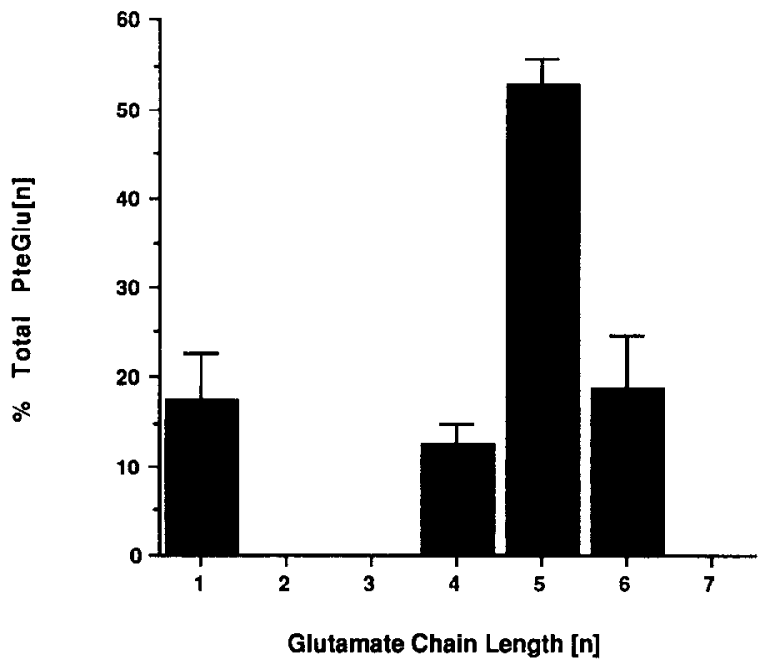

Fig. 2. Distribution of endogenous pteroylpolyglutamates $\left(\mathrm{PteGlu}_{\mathrm{n}}\right)$ in differentiating MELC cultures. MELC cultures were maintained in HMBA-containing medium for 4 days. Endogenous folates in MFLC extracts were quantitatively cleaved to $p$-aminobenzoylpolyglutamates and analyzed by HPLC as described by Shane [10]. Distribution of polyglutamate chain length is expressed as the percentage of total endogenous pteroylglutamate $(2.23 \pm 0.18 \mathrm{nmol} / \mathrm{g}$ cells $)$. Values are the means \pm SEM for 3 determinations.

These initial studies demonstrate the potential usefulness of MELC to study the role of endogenous folate content and the regulation of pteroylpolyglutamate synthesis on uroporphyrinogen synthesis and heme formation in bone marrow during $\mathrm{Pb}$ exposure. 
This research was supported by Grant ES-02424 from the National Institutes of Health.

\section{REFERENCES}

1 Piper, W.N. and Van Lier, R.B.L. (1977) Pteridine regulation of inhibition of hepatic uroporphyrinogen I synthetase activity by lead chloride. Mol. Pharmacol. 13, 1126-1135.

2 Piper, W.N. and Christenson, W.R. (1987) Effect of lead on uroporphyrin and heme content in the bone marrow of rats exposed to nitrous oxide. Ann. NY Acad. Sci. 514, 48-54.

3 Friend, C., Scher, W., Holland, J.G. and Sato, T. (1971) Hemoglobin synthesis in murine virus induced leukemic cells in vitro: stimulation of erythroid differentiation by dimethylsulfoxide. Proc. Natl. Acad. Sci. USA $68,378-382$.

4 Reuben, R.C., Wife, R.L., Breslow, R., Rifkind, R.A. and Marks, P.A. (1976) A new group of potent inducers of differentiation in murine erythroleukemia cells. Proc. Natl. Acad. Sci. USA 73, 862-866.

5 Sassa, S. (1976) Sequential induction of heme pathway enzymes during erythroid differentiation of mouse Friend leukemia virus-infected cells. J. Exp. Med. 143, 305-315.

6 Lowry, O.H.. Rosebrough, N.J., Farr, A.L. and Randall, R.J. (1951) Protein measurement with the Folin phenol reagent. J. Biol. Chem. 193, 265-275.

7 Sassa, S., Granick, S., Bickers, D.R., Bradlow, H.L. and Kappas, A. (1974) A microassay for uroporphyrinogen I synthetase, one of three abnormal enzyme activities in acute intermittent porphyria, and its application to the study of the genetics of this disease. Proc. Natl. Acad. Sci. USA 71, 732-736.

8 Strand, L.J., Meyer, U.A., Felsher, B.F., Redeker, A.G. and Marver, H.S. (1972) Decreased red cell uroporphyrinogen I synthase activity in intermittent acute porphyria. J. Clin. Invest. 51, 2530-2536.

9 Gibson, K.D., Neuberger, A. and Scott, J.J. (1955) The purification and properties of delta-aminolaevulinic acid dehydrase. Biochem. J. 61, 618-629.

10 Shane, B. (1982) High performance liquid chromatography of folates: identification of poly-gammaglutamate chain lengths of labeled and unlabeled folates. Am. J. Clin. Nutr. 35, 599-608.

11 Piper, W.N., Tse, J., Clement, R.P. and Kohashi, M. (1983) Evidence for a folate bound to rat hepatic uroporphyrinogen III cosynthase and its role in the biosynthesis of heme. In: Chemistry and Biology of Pteridines. Waiter de Gruyter \& Co., New York, pp. 415-419. 